\title{
COMMENTARY
}

\section{It's Time to Confront Student Mental Health Issues Associated with Smartphones and Social Media}

\author{
Jeff Cain, EdD, MS \\ University of Kentucky College of Pharmacy, Lexington, Kentucky \\ Submitted October 27, 2017; accepted February 16, 2018; published September 2018.
}

Keywords: smartphones, social media, mental health, anxiety, stress

An increased focus on overall student health and wellness is one of the more recent evolutions in higher education. Pharmacy and other health professions colleges in particular have recognized that well-being is important for students preparing for high-stress health care careers. This awareness has prompted universities and colleges to proactively address risk factors for stress, depression and anxiety, and educate students about the importance of sleep, nutrition, exercise and hobbies. ${ }^{1}$

The current emphasis on student well-being has occurred alongside what many psychiatrists and college counselors have called an emerging mental health crisis at colleges and universities. ${ }^{2,3}$ The American College Health Association (ACHA) conducts an annual national survey that examines the health of college students. From their 2016 survey of 5099 graduate and professional students across 34 schools, the ACHA reports that within the last 12 months, $41.5 \%$ of students "felt things were hopeless," 51.8\% "felt very lonely," 55.3\% "felt overwhelming anxiety," and $33.5 \%$ "felt so depressed that it was difficult to function." for undergraduate students who reported $52.7 \%, 67.3 \%$, $61.9 \%$, and $39.1 \%$ respectively for the same questions. ${ }^{5}$ These reports indicate a growing historical trend from previous years of the study and paint an alarming picture of the mental health status of the college student population. Despite allocating significant financial resources and hiring additional counseling personnel to aid students, many universities struggle to handle the burgeoning demand for counseling and treatment of students struggling in the mental health arena. ${ }^{6}$

There are numerous complex and inter-related factors that may be contributing to the rise of reported mental health issues among college students including economic pressures, psychopharmacology, breakdown of family structures,

Corresponding Author: Jeff Cain, University of Kentucky College of Pharmacy, 114M Lee T. Todd, Jr. Building, 789 South Limestone Dr., Lexington, KY 40536-0596. Tel: 859257-4429. E-mail: jeff.cain@uky.edu intense pressure to succeed academically, high rates of narcissism, and a host of other broad societal, cultural, and personal factors. ${ }^{7}$ However, recent research is beginning to indicate that there may be another underlying factor that is playing a role in college student mental health issues: use of smartphones and social media. Educators have long been concerned with the digital distractions resulting from these relatively new innovations, but some researchers are now suggesting that the combined effects of smartphone and social media use may also negatively affect well-being. ${ }^{8}$ Eiser, a prominent "generations" researcher, has expressed concern that the combined prevalence of smartphones and social media throughout society has created substantial negative effects on today's youth. She correlates the rise in depression and anxiety with the rise in smartphone and social media use, citing a trend that shows without exception, the more time spent on screen activities, the more likely one will be unhappy. ${ }^{9}$ She also connects the growing demands for "safe spaces" and campus speech restrictions to a generation who communicates and socializes primarily online. She explains that most of the "threats" this generation has received have come through social media and texts, and therefore, they are more likely to associate "words" with violence. ${ }^{10}$

Especially in today's political climate, online communications often turn into battles subjecting users to angst and distress. Much has also been written about how social media can adversely affect one's happiness and self-esteem when viewing the highly "curated" lives of others on Facebook, Instagram, etc. ${ }^{11}$ Other members of the popular press have reported that the trend toward digital communications has resulted in students who are lonely in crowds of thousands because they have substituted authentic, face-to-face relationships with virtual friendships (through texts, Facebook, and Instagram) that are void of emotional nourishment. ${ }^{12}$ One of the more troubling aspects with digital afflictions is that the effects are more insidious than overt, making them much more difficult to recognize. One of these effects is the overall psychological toll that these technologies can exert on individuals. Because users remain accessible to others 24 hours a day, it 


\section{American Journal of Pharmaceutical Education 2018; 82 (7) Article 6862.}

becomes more challenging to psychologically disengage from work and other stressful activities. ${ }^{13}$ This has perhaps helped fuel a growing grassroots "unplug" movement, in which individuals voluntarily forego the use of digital technologies for a period of time in order to alleviate mental health issues and reconnect with oneself and one's community. ${ }^{14,15}$

Popular press titles such as "Have smartphones destroyed a generation?" garner attention, but one must be careful to not accept sensationalistic headlines as a true indication of problems. Results of recent research studies, however, do lend a measure of credence to those reports. These research studies reveal a plethora of factors related to smartphones and social media that have negative consequences for sleep, anxiety and depression. In a study of young adults, 20 to 24 years old $(n=4156)$, frequent phone use was associated with higher stress, sleep disturbances, and depression. ${ }^{16}$ Another study of adolescents, 12 to 17 years old $(n=362)$ showed that higher levels of smartphone use at night before bed is also related to shorter sleep patterns and more symptoms of depression. ${ }^{17}$ Results of a study of college students, 18 to 25 years old $(n=249)$, showed a positive relationship between smartphone overuse and level of stress. ${ }^{18}$ Similarly, results from a study of smart device (smartphones or tablets) users $(n=274)$ revealed that higher levels of smart device use was associated with higher levels of stress and depression. ${ }^{19}$ Several studies have also shown that the "fear of missing out" (FOMO) is associated with problematic smartphone use. ${ }^{20}$ FOMO is the "pervasive apprehension that others might be having rewarding experiences from which one is absent." This new phenomenon is exacerbated by the connective natures of smartphones and social media and threatens the psychological health of those unable to un-tether themselves. ${ }^{21}$ In addition to the links between smartphone use and mental health concerns, the effects of various aspects of digital communications themselves are being studied. Toma reports on the overall psychological cost resulting from the self-presentation effects of social media. She summarizes a plethora of recent studies indicating that social media users' comparisons with others often result in envy, depression, reduced happiness, etc. because they perceive others' lives more favorable than their own. ${ }^{22}$

One of the major concerns of psychologists and digital media experts is the propensity toward addiction in today's "attention economy." In their efforts to capture attention (and market share) of users, device and app developers may have unwittingly (or in some cases, intentionally) designed for addiction, by using psychological tricks to develop a craving for the instantaneous "highs" of texts, social media "likes," comments, etc. ${ }^{23,24}$ The trends in drug and alcohol use among the millennial generation has decreased, while the amount of time spent attending to smartphone activity continues to climb. This has led some researchers to suggest that those susceptible to addiction have simply shifted to a new drug: smartphones. ${ }^{9}$ Responding to dings, banners, symbols, and other notification alerts has been shown to be very similar to effects of casino slot machines. Neuroimaging studies show that Internet addiction (of which smartphone and social media addictions are a subset) shows similar increases in activity in brain regions associated with substance-related addictions. ${ }^{25}$ One disturbing research finding related to the issue of addiction is that the mere presence of a smartphone reduces cognitive capacity by keeping the user on "alert," which ultimately adds to the potential psychological toll of the device. ${ }^{26}$ Although, issues with stress, anxiety, and depression are difficult to detect on the surface, it is relatively easy to recognize those with some form of digital addictions. Most of us can probably envision the individual who is tethered to their phone, always keeping it in sight, and checking it relentlessly, despite being in the presence of or in conversations with others. It is also not difficult to picture the image of young adults who browse their phone while lying in bed at night, monitor it for texts and social media notifications throughout the night, and immediately reach for and check their phone upon waking.

If recent research reports associating digital technologies with mental health concerns are merited, it will not be a simple problem to overcome. Because technological advances are considered "progress," it becomes more challenging to admit and confront the negative effects associated with them. Pushing back against smartphone (and by association, social media) use can become very controversial as the overreliance on them is still considered socially acceptable. Smartphones and social media are associated with unprecedented advances in communications, organization, information retrieval, productivity, maintaining social connections, and many other improvements in social and professional spheres. These technologies are largely unquestioned as essential in today's educational and professional environments. It would be difficult to dismiss all the conveniences that these technologies offer and for their roles in numerous advances in health care delivery and health care education. ${ }^{27,28}$ Many educators, in their noble efforts to "meet the students where they live," have taken advantage of the affordances of mobile and social digital technologies by incorporating them into regular instructional activities. ${ }^{29,30}$ Heavy use of these technologies may be considered simply a "way of life" and problems associated with them dismissed as mere woes of those clinging to an outdated culture. ${ }^{31}$ 


\section{American Journal of Pharmaceutical Education 2018; 82 (7) Article 6862.}

Despite all of the positive aspects of smartphones and social media and their acceptance as normal elements of modern life, it may be time to confront the unintended consequences on student lives. The "always on" culture has created unreasonable expectations that users' time, attention, and mental energy constantly be attuned to digital connections. There is almost a presumption that rapid responses to texts, messages, social media posts are a customary norm. ${ }^{32}$ We should not just bemoan and accept these issues as unfortunate consequences of progress. If we are serious about providing a "holistic" approach to student development and wellness, we must consider the emerging issues regarding mobile digital technologies as a legitimate factor with regard to mental health. Although a call for action regarding digital technologies and wellness within pharmacy and health professions education might be considered somewhat premature, we would not be the first to react. Psychiatrists have already begun to recommend that students identified as suffering from anxiety or depression should be monitored for smartphone addiction. ${ }^{33}$ The Royal Society of Public Health has also called for education in UK public schools regarding safe use of social media, and a digital media component in the training of those supporting health and wellness. ${ }^{34}$

As health care educators, our first step should be to recognize the potential issues associated with smartphone use and critically examine the literature to understand the nature of the problems. As with most things, more research is needed to establish cause and effect (not just correlation) and to determine how prevalent the issues are or are becoming in health professions education. It is not yet clear whether smartphone and social media use leads to mental health issues directly or whether individuals vulnerable to the issues are more susceptible to use these technologies as a coping mechanism that in turn, exacerbates the problems. We are just now entering an era in which anxiety and depression are major threats to the greater student population's academic success and overall wellness, therefore it will take time to unravel all the causes and potential solutions. Pharmacy school counselors and student affairs personnel who work with students suffering from mental health issues will be critical in determining the extent of problems associated with smartphones and social media and the effectiveness of strategies to counteract them. Second, although much more is to be learned, enough is known to begin making our students aware of the connections between mental health and smartphones. We should begin to incorporate information regarding digital afflictions in our wellness education and promotions. Research regarding prevention and treatment of digital affliction is still ongoing, but some of the suggested strategies to help alleviate the issues may include mindfulness training, turning off phone and app notifications, removing devices from bedrooms, and setting time and use limits. ${ }^{16,17,35,36}$ Cognitive behavioral therapy has been used to treat forms of Internet addictions and is also considered a potential viable treatment for overuse of smartphones and digital media. ${ }^{37,38}$

Finally, we need to understand how to maximize the use of these technologies for education and professional purposes, while helping our future health care practitioners recognize the risks of stress, anxiety, and depression that may accompany them. Because of the numerous positive attributes of these technologies, they will not be going away anytime soon; therefore, we must learn to adapt their uses in a way that is both beneficial and psychologically healthy. This is far from a simple issue, but it appears to be becoming an increasingly important one.

\section{REFERENCES}

1. Anderson DS. Wellness Issues for Higher Education: A Guide for Student Affairs and Higher Education Professionals. New York, NY: Routledge; 2015.

2. Henriques G. The college student mental health crisis. https:// www.psychologytoday.com/blog/theory-knowledge/201402/thecollege-student-mental-health-crisis. Accessed March 14, 2017.

3. Eiser A. The crisis on campus. Am Psychol Assoc. 2011;42(8):18. 4. American College Health Association. National College Health Assessment II - Graduate/Professional Student Reference Group Data Report Fall 2016. http://www.acha-ncha.org/docs/NCHA-II_FALL_ 2016_GRADUATE_REFERENCE_GROUP_DATA_REPORT.pdf. Accessed October 6, 2017.

5. American College Health Association. National College Health Assessment II - Undergraduate Student Reference Group Data Report Fall 2016. http://www.acha-ncha.org/docs/NCHA-II\%20SPRING\% 202016\%20UNDERGRADUATE\%20REFERENCE\%20GROUP\% 20DATA\%20REPORT.pdf. Accessed January 31, 2018.

6. Wilson R. An epidemic of anguish. Chron Higher Educ. http:// chronicle.com/article/An-Epidemic-of-Anguish/232721. Accessed May 31, 2016.

7. Henriques G. What is causing the college student mental health crisis? Psychol Today; https://www.psychologytoday.com/blog/ theory-knowledge/201402/what-is-causing-the-college-studentmental-health-crisis. Accessed October 5, 2017.

8. Brazeau GA, Brazeau DA. The challenge of educating in a highlyconnected and multitasking world. Am J Pharm Educ. 2009;73(7): Article 125.

9. Twenge JM. Have smartphones destroyed a generation? https:// www.theatlantic.com/magazine/archive/2017/09/has-thesmartphone-destroyed-a-generation/534198/. Accessed October 6, 2017.

10. Twenge JM. The smartphone geneartion vs. free speech. https:// www.wsj.com/articles/the-smartphone-generation-vs-free-speech1504274890. Accessed October 9, 2017.

11. Stephens-Davidowitz S. Don't let Facebook make you miserable. https://www.nytimes.com/2017/05/06/opinion/sunday/dont-letfacebook-make-you-miserable.html. Accessed October 9, 2017. 12. Brody JE. Hooked on our smartphones. https://www.nytimes. com/2017/01/09/well/live/hooked-on-our-smartphones.html. Accessed October 6, 2017. 


\section{American Journal of Pharmaceutical Education 2018; 82 (7) Article 6862.}

13. Sleek S. The psychological toll of the smartphone. https://www. psychologicalscience.org/observer/the-psychological-toll-of-thesmartphone. Accessed October 9, 2017.

14. Huffington Post. National day of unplugging 2013: 6 health reasons you should spend time tech-free. https://www.huffingtonpost. com/2013/03/02/national-day-of-unplugging-health-reasonsunplug_n_2791658.html. Accessed January 31, 2018.

15. National day of unplugging. https://www.nationaldayofunplugging. com/. Accessed January 31, 2018.

16. Thomée S, Härenstam A, Hagberg M. Mobile phone use and stress, sleep disturbances, and symptoms of depression among young adultsa prospective cohort study. BMC Pub Health. 2011;11(1):66-76.

17. Lemola S, Perkinson-Gloor N, Brand S, Dewald-Kaufmann JF, Grob A. Adolescents' electronic media use at night, sleep

disturbance, and depressive symptoms in the smartphone age. J Youth Adolesc. 2015;44(2):405-418.

18. Samaha M, Hawi NS. Relationships among smartphone addiction, stress, academic performance, and satisfaction with life. Comput Human Behav. 2016;57:321-325.

19. Harwood J, Dooley JJ, Scott AJ, Joiner R. Constantly connected the effects of smart-devices on mental health. Comput Human Behav. 2014;34:267-272.

20. Elhai JD, Levine JC, Dvorak RD, Hall BJ. Fear of missing out, need for touch, anxiety and depression are related to problematic smartphone use. Comput Human Behav. 2016;63:509-516. 21. Przybylski AK, Murayama K, DeHaan CR, Gladwell V. Motivational, emotional, and behavioral correlates of fear of missing out. Comput Human Behav. 2013;29(4):1841-1848.

22. Toma CL. Taking the good with the bad: effects of Facebook self-presentation on emotional well-being. In: Reinecke L, Oliver MB, eds. The Routledge Handbook of Media Use and Well-being. Abingdon, United Kingdom: Routledge; 2016.

23. Lewis P. 'Our minds can be hijacked': the tech insiders who fear a smartphone dystopia. https://www.theguardian.com/technology/ 2017/oct/05/smartphone-addiction-silicon-valley-dystopia. Accessed October 16, 2017.

24. Alter A. Irresistible: The Rise of Addictive Technology and the Business of Keeping Us Hooked. New York, NY: Penguin Press; 2017. 25. Kuss DJ, Griffiths MD. Internet and gaming addiction: a systematic literature review of neuroimaging studies. Brain Sci. 2012;2(3):347-374.
26. Ward AF, Duke K, Gneezy A, Bos MW. Brain drain: the mere presence of one's own smartphone reduces available cognitive capacity. J Assoc Consum Res. 2017;2(2):140-154.

27. Kamel Boulos MN, Wheeler S. The emerging Web 2.0 social software: an enabling suite of sociable technologies in health and health care education. Health Info Libr J. 2007;24(1):2-23.

28. Grajales III FJ, Sheps S, Ho K, Novak-Lauscher H, Eysenbach G. Social media: a review and tutorial of applications in medicine and health care. J Med Internet Res. 2014;16(2):e13.

29. Cheston CC, Flickinger TE, Chisolm MS. Social media use in medical education: a systematic review. Acad Med. 2013;88(6): 893-901.

30. Gikas J, Grant MM. Mobile computing devices in higher education: student perspectives on learning with cellphones, smartphones \& social media. Internet Higher Educ. 2013; 19:18-26.

31. Thompson WE, Thompson ML. Smartphones: addiction, or way of life? J Ideology. 2017;38(1):Article 3.

32. Turkle S. Always-on/always-on-you: the tethered self. In: Katz JE, ed. Handbook of Mobile Communication Studies. Cambridge, MA: The MIT Press; 2008:121-137.

33. Demirci K, Akgönül M, Akpinar A. Relationship of smartphone use severity with sleep quality, depression, and anxiety in university students. J Behav Addict. 2015;4(2):85-92.

34. Royal Society of Public Health. \#StatusOfMind: social media and young people's mental health and wellbeing. https://www.rsph. org.uk/our-work/policy/social-media-and-young-people-s-mentalhealth-and-wellbeing.html. Accessed October 17, 2017.

35. Grossman P, Niemann L, Schmidt S, Walach H. Mindfulnessbased stress reduction and health benefits: a meta-analysis. $J$ Psychosom Res. 2004;57(1):35-43.

36. Peck E. Turn off the notifications on your phone. They're ruining your life! https://www.huffingtonpost.com/entry/how-to-turn-offsmartphone-notifications_us_55a3fe3be4b0ecec71bc94bb. Accessed October 25, 2017.

37. Young KS. Cognitive behavior therapy with Internet addicts: treatment outcomes and implications. Cyberpsychol Behav. 2007;10(5):671-679.

38. Young KS. Treatment outcomes using CBT-IA with Internetaddicted patients. $J$ Behav Addict. 2013;2(4):209-215. 